Disponível em

http://www.anpad.org.br/rac

RAC, Rio de Janeiro, v. 19, n. 3, art. 2, pp. 311-335, Maio/Jun. 2015

http://dx.doi.org/10.1590/1982-7849rac20151704

$($ (c) EY-No

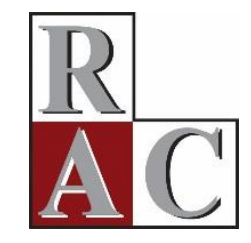

\title{
Impacto da Adoção das Normas Internacionais de Contabilidade na Área da Controladoria
}

\begin{abstract}
Impact of the Adoption of International Accounting Standards in the Area of Controllership
\end{abstract}

Ilse Maria Beuren Universidade Federal de Santa Catarina - UFSC

Dalci Mendes Almeida Universidade Regional de Blumenau - FURB

Artigo recebido em 01.11.2013. Última versão recebida em 15.08.2014. Aprovado em 19.08.2014. 


\title{
Resumo
}

Este estudo objetiva verificar o impacto da adoção das normas internacionais de contabilidade, sob a lente da Teoria da Estruturação, na área da controladoria de empresas do Novo Mercado da BM\&FBovespa. Um levantamento foi realizado nas 118 empresas listadas no Novo Mercado da BM\&FBovespa, e a amostra constituiuse das 36 empresas respondentes. Um questionário, elaborado com base nos estudos de Macintosh e Scapens (1990, 1991), Barrachina (2001), Giddens (2003), Junquilho (2003) e Busco (2009), foi enviado aos controllers e/ou pessoas da controladoria que participaram do processo de adoção das normas internacionais de contabilidade. Aos dados coletados aplicaram-se as técnicas estatísticas de análise fatorial e correlação canônica. Os resultados apontam que o processo de convergência impactou na estrutura da controladoria, e a ação se refletiu nesta estrutura. Nela, novas regras sociais e recursos influenciaram a ação dos gestores, por meio da discussão e do poder de influência, legitimando novas normas e valores. A ação impactou na estrutura, o que evidencia a dualidade desta quando em interação, preconizada por Giddens $(1979,1996,2003)$. Conclui-se que o processo de adoção das normas internacionais de contabilidade impactou a área organizacional da controladoria e provocou a produção e a reprodução de sua ordem social.

Palavras-chave: teoria da estruturação; normas internacionais de contabilidade; controladoria.

\begin{abstract}
This study aims to investigate, under the lens of the Structuration Theory, the impact the adoption of international accounting standards has on the Controllership area of BM\&F Bovespa New Market companies. A survey was done in 118 companies listed on the BM\&F Bovespa New Market, with a final sample of respondents from 36 companies. A questionnaire based on Macintosh and Scapens (1990, 1991), Barrachina (2001), Giddens (2003), Junquilho (2003), and Busco (2009) was sent to controllers and/or people in Controllership who participated in the international accounting standards adoption process. Factor analysis and canonical correlation were applied to the data. The results show that the convergence process impacted Controllership structure and that action is reflected in the structure. New social rules and resources influenced the managers' actions in the structure through discussion and the power of influence, legitimizing new norms and values. Action impacted the structure, showing the duality of structure in interaction, as advocated by Giddens (1979, 1996, 2003). The conclusion is that the process of adopting international accounting standards impacted the organizational area of Controllership and caused the production and reproduction of their social order.
\end{abstract}

Key words: structuration theory; international accounting standards; controllership. 


\section{Introdução}

A controladoria, enquanto órgão organizacional responsável pelo gerenciamento das informações, com a adoção das normas internacionais de contabilidade, passou a realizar e a apoiar novos procedimentos de mensuração e evidenciação, como aplicação do valor justo, impairment test, do ajuste ao valor presente, do custo atribuído, entre outros conceitos e técnicas que se refletem nas informações geradas para os usuários das informações contábeis da empresa. Isso altera funções da controladoria e das atribuições dos controllers e dos demais envolvidos nessa área organizacional (Beuren \& Almeida, 2012).

Miller (1994, p. 1) destaca "que a contabilidade exerce influência e, por sua vez, é influenciada por uma multiplicidade de agentes, órgãos, instituições e processos". Evidências de que o uso da contabilidade dentro do processo de gestão vem mudando são destacadas por Burns e Scapens (2000), que citam, como exemplo, a utilização pelos gestores de sistemas contábeis e de relatórios financeiros, de forma mais flexível, compostos por indicadores de resultados financeiros e não financeiros. Nesse sentido, argumentam que o estudo dos processos de mudança da contabilidade de suporte ao processo de gestão implica consubstanciar as formas pelas quais novas práticas contábeis evoluem.

A adoção das normas internacionais implicou várias mudanças, seja na estrutura de tecnologia da informação, seja nas políticas e processos de relatórios financeiros, afetando diversos elementos integrantes, tanto no que se refere às técnicas e tecnologias quanto nos aspectos comportamental e organizacional (Taipaleenmäki \& Ikäheimo, 2011). Essas mudanças causaram impacto na área da controladoria, em termos de estrutura (regras e recursos) e de interação (ação dos agentes), em decorrência do uso das informações por ela disponibilizadas às diversas áreas da empresa.

Angelkort, Sandt e Weißenberger (2008) reportam que a adoção dos International Financial Reporting Standards (IFRS), ou seja, dos Padrões de Relatórios Financeiros Internacionais, causa impacto na controladoria, uma vez que planejamentos internos e comunicação de dados gerados pelos sistemas de controle são utilizados para fins de IFRS. Além disso, ressaltam que o banco de dados de IFRS pode ser utilizado pela controladoria, que se constitui em um sistema de contabilidade integrado. Nessa perspectiva, amplia-se o papel da contabilidade para além da dimensão técnica, o que implica em escolhas contábeis.

A adoção das IFRS trouxe novos procedimentos para a área da controladoria, o que pode ter exigido a implantação de novas funções ou a reestruturação das já existentes, além de demandas adicionais do controller por parte dos usuários das informações nas organizações. A contabilidade é um mecanismo que permeia a estrutura das organizações e as instituições sociais, não apenas como uma tecnologia, mas, segundo Miller (2001), com os propósitos de aumentar a eficiência e a competitividade, promover o crescimento econômico da organização, além de melhorar a tomada de decisão e incentivar a responsabilidade dos gestores. Miller (1994, p. 4) explica que "a prática da técnica contábil é intrínseca e irremediavelmente social". Denota-se a importância de estudar a contabilidade sob a lente de teorias sociológicas, como é o caso da Teoria da Estruturação.

A Teoria da Estruturação, conforme preconizada por Giddens (1979, 1996, 2003), utiliza o conceito central da dualidade da estrutura em interação, a qual prevê que a estrutura, formada pelas regras e recursos, impacta na ação dos agentes e vice-versa. Macintosh (1985) demonstrou o potencial da Teoria da Estruturação como um dispositivo de sensibilização na pesquisa em contabilidade gerencial, ilustrando como a contabilidade representa as dimensões de legitimação, significação e dominação. Também demonstrou o papel da agência na mudança de sistemas de controle gerencial. Macintosh e Scapens (1991) observam que pesquisadores em contabilidade vêm reconhecendo que não podem limitar suas pesquisas às questões técnicas e econômicas.

Em âmbito internacional, a Teoria da Estruturação foi investigada na área contábil em ensaios teóricos (Araújo, 2003, Barley \& Tolbert, 1997; Barrachina \& Ripoll, 2006; Busco, 2009; Macintosh, 1985; Roberts \& Scapens, 1985), no contexto da implantação de sistemas de controle gerencial (Conrad, 2005; Dirsmith, Heian, \& Covaleski, 1997; Macintosh \& Scapens, 1990, 1991) e na adoção de normas 
relativas ao European Union Emissions Trading System (EU ETS), tendo como base os fundamentos de Norman Macintosh para a análise contábil fundamentada na Teoria da Estruturação (Moore, 2011).

Em âmbito nacional, a Teoria da Estruturação foi essencialmente pautada em Giddens (1979, 1996, 2003) por meio de ensaios teóricos, como o de Machado-da-Silva, Guarido e Rossoni (2006), que propõem que essa teoria, baseada na lógica de recursividade entre agência e estrutura, é adequada para o entendimento do campo de maneira dinâmica; de Nogueira (2010), que compara o conceito de rotinas nas abordagens do paradigma funcionalista e da Teoria da Estruturação; de Peci (2003), que analisa a relação objetividade-subjetividade e sua presença no campo de estudos organizacionais; de M. L. Almeida e Sales (2011), que apontam distanciamentos e aproximações entre o campo da estratégia como prática e a discussão da Teoria da Estruturação; de Lima e Carvalho (2011), que analisam a evolução das teorias sobre liderança à luz da Teoria da Estruturação.

Alguns estudos teórico-empíricos também foram identificados, como o de Costa e Carvalho (2006), que evidenciam construções discursivas por meio das quais os dirigentes de organizações brasileiras valem-se de dinâmicas e propriedades estruturais para a (re)produção de relações sociais na esfera da Responsabilidade Social Empresarial; de Machado-da-Silva e Rossoni (2007), que examinam como o nível de coesão estrutural dos pesquisadores da área de estratégia no Brasil condiciona a construção do conhecimento nesse campo social; de Rodrigues (2008), que recorre a um quadro de análise estruturacionista para entender as particularidades das organizações sem fins lucrativos como fenômeno organizacional.

Depreende-se que a Teoria da Estruturação vem sendo investigada em diferentes perspectivas da área da Administração no Brasil. Este cenário não se replica com a mesma intensidade em pesquisas da área da Contabilidade, embora se tenham observado referências a essa teoria. Wanderley e Cullen (2012) consideraram-na como base de investigação, para explicar a dinâmica política e social do processo de mudança na contabilidade gerencial em uma companhia de distribuição elétrica brasileira privatizada. Beuren e Almeida (2012) a utilizaram para analisar os impactos da implantação das normas internacionais de contabilidade na controladoria em uma empresa industrial têxtil, no pressuposto de que o processo da convergência contribui para a produção e a reprodução da ordem social.

Assim, com o intuito de compreender a dinâmica do campo do órgão organizacional da controladoria, fundamentado em um quadro estruturacionista, nas dimensões de legitimação, significação e dominação, elaborou-se a seguinte questão de pesquisa: Qual o impacto da adoção das normas internacionais de contabilidade, sob a lente da Teoria da Estruturação, na área da controladoria de empresas do Novo Mercado da BM\&FBovespa? O objetivo do estudo é verificar o impacto da adoção das normas internacionais de contabilidade, sob a lente da Teoria da Estruturação, na área da controladoria de empresas do Novo Mercado da BM\&FBovespa.

Esta pesquisa difere da realizada por Moore (2011), que, fundamentado na Teoria da Estruturação, observou na norma contábil IFRIC 3, relativa ao EU ETS, uma contradição estrutural, que resultou em desequilíbrios de medição e tensão, levando inclusive à retirada da IFRIC 3 e à coalizão do IASB e do FASB para desenvolver orientações sobre a contabilização de ETS. Difere também da pesquisa de Wanderley e Cullen (2012), que buscou explicar a dinâmica política e social do processo de mudança na contabilidade gerencial em uma companhia, considerando o seu ambiente com a lógica inter e intraorganizacional.

De modo tangencial, ainda faz alusão aos estudos de Macintosh e Scapens (1990, 1991), Barrachina (2001), Giddens (2003), Junquilho (2003) e Busco (2009), ao considerar as variáveis e subvariáveis propostas por esses autores na construção do instrumento de pesquisa. No entanto, diferencia-se no campo de investigação desses estudos, ao verificar o impacto da adoção das normas internacionais de contabilidade na controladoria, analisando a produção e reprodução da sua ordem social, com vistas a identificar como as normas internacionais de contabilidade impactaram o sistema social da controladoria. Todavia, assemelha-se ao escopo do estudo de Beuren e Almeida (2012), mas substitui a estratégia de pesquisa de estudo de caso por uma pesquisa de levantamento, logo, diferenciase nos aspectos decorrentes. 


\section{Convergência às Normas Internacionais de Contabilidade e suas Implicações na Controladoria}

O processo de convergência contábil possui como objetivo integrar as práticas contábeis entre os países, atendendo a necessidade de informação contábil padronizada por parte dos usuários, principalmente dos mercados financeiros e de capitais. Esse processo busca harmonizar diferenças de padrões contábeis existentes, tornando possível a comparabilidade da informação com os Generally Accepted Accounting Principles (GAAP) e a maior mobilidade de capitais entre as economias envolvidas (Oliveira \& Lemes, 2011).

Algumas dificuldades são enfrentadas com a adoção do processo de convergência contábil. Niyama (2009) destaca que os critérios de avaliação, apropriação e classificação contábil, determinados pela legislação fiscal, geram uma dificuldade maior para que a harmonização aconteça. Weffort (2005) menciona que, se não forem consideradas as diferenças nacionais de cada país, como cultura, economia, sistemas jurídicos e fiscais, a adoção das normas internacionais de contabilidade pode não resultar em harmonização efetiva.

No Brasil, o processo de convergência aconteceu com a promulgação da Lei n. 11.638, de 28 de dezembro de 2007, que estabeleceu mudanças contábeis na legislação societária, além da adoção dos Pronunciamentos Contábeis, emitidos pelo Comitê de Pronunciamentos Contábeis, de aplicação obrigatória pelas empresas a partir do exercício social encerrado em 2010. A adoção desses CPCs trouxe várias alterações nas normas contábeis em termos de mensuração, reconhecimento e evidenciação, exigindo mudanças nos sistemas de informações contábeis das empresas, o que influenciou na estrutura e no comportamento das pessoas da controladoria.

De acordo com Mosimann e Fisch (1999), a controladoria pode ser definida sob dois enfoques: como unidade administrativa e como área do conhecimento. Para esses autores, a controladoria, enquanto unidade administrativa, tem a finalidade de: (a) garantir informações adequadas ao processo decisório; (b) colaborar com os gestores em seus esforços de obtenção da eficácia de suas áreas; (c) assegurar a eficácia empresarial por meio da coordenação dos esforços dos gestores das áreas. Já como área do conhecimento, recebe contribuições de diversas ciências que, de alguma forma, tangenciem aspectos organizacionais.

No presente estudo, a controladoria foi considerada uma unidade administrativa, responsável pela coordenação e disseminação das informações de suporte ao processo de gestão. Nessa perspectiva, ela busca direcionar os esforços dos gestores de modo que conduzam as decisões e as ações de sua área de responsabilidade à otimização do resultado global da organização (L. B. Almeida, Parisi, \& Pereira, 1999). Esse conjunto de funções e atividades tende a impactar na estrutura da controladoria, e a refletir a ação dos agentes na estrutura, conforme previsto na Teoria da Estruturação, por meio da Dualidade da Estrutura.

\section{Pilares da Teoria da Estruturação na Controladoria}

A Teoria da Estruturação aborda "a interação das ações dos agentes e as estruturas sociais na produção, reprodução e regulação de toda a ordem social" (Macintosh \& Scapens, 1990, p. 459). Segundo Giddens (2003, p. 22), "uma das principais proposições da Teoria da Estruturação é que as regras e os recursos esboçados na produção e na reprodução da ação social são, ao mesmo tempo, os meios de reprodução do sistema (dualidade de estrutura)".

Dualidade da estrutura, conforme Macintosh e Scapens (1990, p. 456), "significa que as estruturas sociais são constituídas pela ação humana (agência) e, ao mesmo tempo, são o meio desta constituição". Segundo Giddens (2003, p. 30), "crucial para a ideia de estruturação é o teorema da dualidade da 
estrutura, que está logicamente subentendido nos argumentos apresentados sobre estrutura, sistema e estruturação".

As estruturas, conforme Busco (2009, p. 250, tradução nossa), "são modelos abstratos que guiam o comportamento humano. Em particular, elas representam as regras e os recursos, ou conjuntos de relações de transformação ... em sistemas sociais". Giddens (2003) explica que as regras podem ser classificadas como elementos normativos e códigos de significação; e os recursos podem ser impositivos e alocativos. Para Giddens (2003, p. 15), "os recursos impositivos derivam da coordenação das atividades dos agentes humanos, e os recursos alocativos são procedentes do controle de produtos materiais ou de aspectos do mundo material". Giddens $(1979,2003)$ destaca que, por meio da estrutura (regras e recursos), a Teoria da Estruturação permite realizar a análise institucional, sendo metodologicamente considerado um nível de análise.

Os sistemas sociais são formados pelas atividades de agentes humanos, desenvolvidas pelo tempo e espaço (Busco, 2009). De acordo com Giddens (2003, p. 444), os sistemas sociais são "a padronização de relações sociais ao longo do tempo-espaço, entendidas como práticas reproduzidas". Analisar "a estruturação das práticas sociais é procurar explicar como a estrutura se produz por intermédio da ação e, reciprocamente, como a ação é constituída estruturalmente" (Giddens, 1996, p. 183). Na estruturação, estudam-se os modos como tais sistemas são produzidos e reproduzidos, por meio das atividades de conhecimento dos atores, que se apoiam em regras e recursos no contexto da ação (Giddens, 2003).

Junquilho (2000, p. 39) menciona que, em função da dualidade da estrutura, "a ação humana pode constituir (produzir) propriedades estruturais dos sistemas sociais, bem como, pode ser constituída (reproduzida) por essas mesmas propriedades". Assim, além da estrutura, a Teoria da Estruturação está preocupada com a interação das ações, ou seja, com a agência. Para Giddens (2003, p. 10), a "agência não se refere às intenções que as pessoas têm ao fazer as coisas, mas à capacidade delas para realizar essas coisas em primeiro lugar". Macintosh e Scapens (1990, p. 458) explicam que "agência, conforme Giddens, refere-se às ações tomadas pelos indivíduos em contextos sociais".

De acordo com Giddens $(1979,2003)$, por meio da agência humana, ou seja, das ações dos atores sociais, a Teoria da Estruturação permite a análise da conduta estratégica, sendo considerado metodologicamente um segundo nível de análise. A análise institucional e a análise da conduta estratégica são consideradas dois níveis de análise complementares, em função da Dualidade da Estrutura (Giddens, 1979, 2003).

Denota-se, então, que agência e estrutura estão relacionadas, e que o processo de estruturação acontece por meio da ligação entre a estrutura e a interação das ações dos agentes, as regras e recursos influenciam na ação dos agentes e a ação destes influencia na estrutura. Essas relações fundamentam-se nos pilares da Teoria da Estruturação. Giddens $(1979,1996,2003)$ utiliza três dimensões de estruturas sociais que constituem os pilares da Teoria, as quais são: significação em interação com comunicação, dominação em interação com poder e legitimação em interação com sanção, conforme demonstrado na Figura 1.

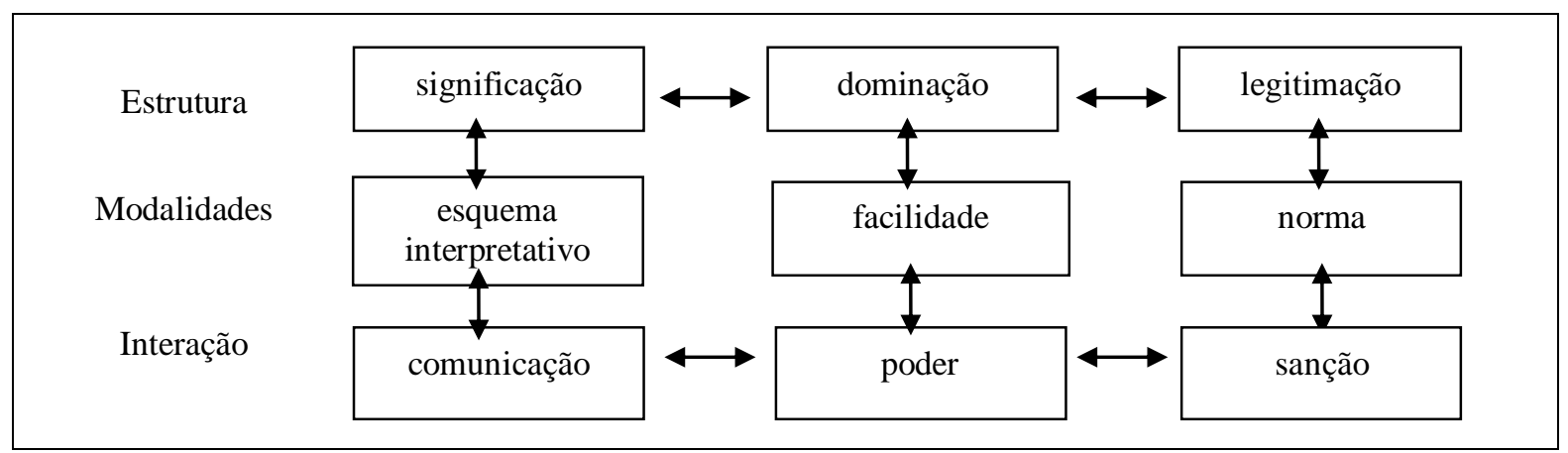

Figura 1. Modelo da Dualidade da Estrutura em Interação

Fonte: Adaptada de Giddens, A. (2003). A constituição da sociedade (p. 34). São Paulo: Martins Fontes. 
O modelo da dualidade da estrutura em interação é o processo pelo qual Giddens (2003) concilia estrutura e ação social (interação), possibilitando a estruturação de sistemas sociais e representando, conforme Junquilho (2000), a reprodução e a produção da vida social. Segundo Junquilho (2000, p. 46), parte-se do princípio de que "a mediação da conduta humana pela estrutura, bem como a constituição dessa mesma estrutura através da ação humana, acontecem de forma simultânea, exprimindo a vinculação entre as rotinas das ações cotidianas e propriedades institucionalizadas da vida social".

As modalidades, compostas por esquema interpretativo, facilidade e norma, são mediadoras da estrutura e da interação, e expressam a cognoscitividade dos agentes sociais em cada dimensão da estrutura. Para Giddens (2003, p. 440), a cognoscitividade é "tudo que os atores sabem (creem) acerca das circunstâncias de sua ação e da de outros, apoiados na produção e na reprodução dessa ação, incluindo tanto o conhecimento tácito quanto o discursivamente disponível”. De acordo com Junquilho (2000), tais modalidades são utilizadas pelos agentes para realizar a produção da interação e, ao mesmo tempo, provocar a reprodução das estruturas, nas mesmas dimensões da interação.

Cánepa, Brodbeck e Fetzner (2008) mencionam que a estruturação começa por um estágio cognitivo, passa para um estágio regulativo e, finalmente, o processo evolui para um estágio normativo. O estágio cognitivo é formado pela comunicação das regras entre os agentes, as quais geram os recursos que são utilizados para atingir os objetivos, por meio da dominação, que forma o estágio regulativo, e, por fim, tem-se o estágio normativo, em que a norma é legitimada por pressões morais e sociais.

Junquilho (2000, p. 48) alerta que é importante observar "que a divisão entre as dimensões da estrutura e da interação é apenas analítica, dado que o processo de estruturação pressupõe o vínculo entre estrutura e interação pela intermediação das modalidades". Denota-se que a Teoria da Estruturação, por meio dos seus pilares, envolve regras, recursos e ações que permeiam as atividades de uma organização ou de uma área organizacional, como a unidade organizacional da controladoria, permitindo conhecer sua ordem social.

As funções e as atividades desenvolvidas pelos controllers e demais agentes da controladoria constituem-se em práticas sociais, uma vez que envolvem procedimentos, métodos, técnicas, visando ao desenvolvimento de suas próprias atividades num cenário de várias diferenças, complexidades e mudanças (Beuren \& Almeida, 2012). Os sistemas de contabilidade gerencial, de acordo com Barrachina e Ripoll (2006, p. 159), "podem ser analisados como sendo um conjunto de atividades, produzidos e reproduzidos por diferentes atores (conceito de sistema social), contribuindo, na prática, para a produção e reprodução da vida organizacional".

Hopwood (1987, p. 213) já advertia que, "de fato, a contabilidade é considerada como um dos meios importantes pelos quais a organização é incorporada ao domínio social". Os sistemas de contabilidade gerencial, segundo Macintosh e Scapens (1990), representam modalidades de estruturação em três dimensões, que são: significação, dominação e legitimação. Tais dimensões podem ser retiradas da abordagem sobre a interpretação da natureza e o papel das práticas contábeis.

O pilar de significação compreende as regras compartilhadas, conceitos e teorias que são delineados para fazer sentido nas atividades organizacionais. A contabilidade gerencial é um meio para os gestores acompanharem as atividades da organização e permite que os mesmos se comuniquem com conhecimento profundo sobre suas atividades (Busco, 2009). O gerenciamento de um sistema de contabilidade é uma interpretação que faz a ligação entre a estrutura de significação e a interação social na forma de comunicação entre os agentes. Assim, a estrutura de significação compreende as regras compartilhadas, os conceitos e as teorias que são utilizadas para dar sentido às atividades organizacionais (Macintosh \& Scapens, 1990).

No que se refere à dominação, Macintosh e Scapens (1990) relatam que, nessa dimensão, os sistemas de contabilidade gerencial representam as facilidades que podem ser utilizadas pelos gestores para coordenar e controlar os participantes de diferentes níveis hierárquicos. Vatter (1950, p. 238) menciona que "a natureza da controladoria pode ser encontrada nas relações de dar e receber, em vários níveis de execução nos quais o controller exerce influência, e faz contribuições úteis à eficácia 
gerencial”. Giddens (1979) aponta a dominação do saber-fazer, afirmando que, no caso da controladoria, há uma dominação por um saber-fazer que está circunscrito aos agentes que comungam de certo conhecimento. Trata-se dos pressupostos implícitos de dominação na construção dos domínios de significação, conforme Berger e Luckmann (1973).

Quanto ao pilar de legitimação, segundo Barrachina (2001, p. 89), "os sistemas de contabilidade gerencial são utilizados por diferentes atores para legitimar seu comportamento sobre os outros ou as decisões, consolidando o que é atribuído". Macintosh e Scapens (1990, p. 462) destacam que, na dimensão de legitimação, "os sistemas de contabilidade comunicam um conjunto de valores e ideais sobre o que é aprovado e o que é reprovado; justificam os direitos de alguns participantes e consideram os outros responsáveis; e legitimam o uso de certas recompensas e sanções". Para Giddens (1979), a legitimação das práticas sociais é que viabilizam as formas de dominação. Nesse sentido, a legitimação das normas internacionais de contabilidade pode ser uma possibilidade de dominação.

Depreende-se do exposto que os pilares da Teoria da Estruturação podem contribuir para o entendimento da dinâmica do campo pretendido nesta pesquisa. Os estudos apontados sugerem que os pilares estão relacionados com as práticas da contabilidade. Várias alterações, como as decorrentes do processo de convergência às normas internacionais de contabilidade, vêm sendo imputadas a essas práticas, o que pode alterar a ordem social na área organizacional da controladoria.

\section{Método e Procedimentos da Pesquisa}

Pesquisa descritiva foi realizada a partir de um levantamento em empresas sobre o impacto da adoção das normas internacionais de contabilidade na área organizacional da controladoria, relacionando-se a estrutura e a ação dos agentes envolvidos, conforme preconizado na Teoria da Estruturação. A população da pesquisa compreendeu as empresas listadas no segmento do Novo Mercado da BM\&FBovespa. Segundo a Bolsa de Valores, Mercadorias e Futuros Bovespa (BM\&FBovespa, n.d.), "o novo mercado é um segmento de listagem destinado à negociação de ações emitidas por companhias que se comprometam, voluntariamente, com a adoção de práticas de governança corporativa adicionais em relação ao que é exigido pela legislação".

O comprometimento voluntário, a adoção de práticas de governança corporativa adicionais, bem como a obrigatoriedade de adoção das normas contábeis internacionais, são fatores que aumentam a possibilidade de contribuição ao estudo e justificam a escolha desse segmento como população da pesquisa. A população inicial compreendeu as 118 empresas listadas no rol do novo mercado da BM\&FBovespa. No entanto, a amostra final foi constituída das 36 empresas respondentes da pesquisa, o que representa $30,51 \%$ da população, configurando-se como uma amostra por acessibilidade.

Os sujeitos da pesquisa foram as pessoas que fizeram parte da controladoria e que estiveram ligadas de alguma forma ao processo de adoção das normas internacionais de contabilidade. Os respondentes poderiam ser o controller, o coordenador da contabilidade financeira, o coordenador da contabilidade gerencial, o analista sênior e o analista júnior.

\section{Variáveis e instrumento de pesquisa}

Para atender ao objetivo da pesquisa e operacionalizá-lo, foi desenvolvido o constructo evidenciado na Tabela 1. 
Tabela 1

\section{Constructo da Pesquisa}

\begin{tabular}{|c|c|c|}
\hline Variáveis & Subvariáveis & Perguntas \\
\hline \multirow[t]{2}{*}{ Significação } & Funções & $\begin{array}{l}\text { Quais os impactos da adoção das normas internacionais de contabilidade nas } \\
\text { funções da área organizacional controladoria que seguem? ( ) Função Contábil; } \\
\text { ( ) Função Gerencial Estratégica; ( ) Função de Custos; ( ) Função Tributária; } \\
\text { ( ) Função de Proteção e Controle de Ativos; ( ) Função de Controle e Riscos; } \\
\text { ( ) Função de Controle Interno; ( ) Função de Gestão da Informação. }\end{array}$ \\
\hline & $\begin{array}{l}\text { Atividades da } \\
\text { Controladoria }\end{array}$ & $\begin{array}{l}\text { Quais os impactos da adoção das normas internacionais de contabilidade nas } \\
\text { atividades da área organizacional controladoria que seguem? ( ) Elaboração e } \\
\text { evidenciação dos relatórios; ( ) Definição de premissas para elaboração do } \\
\text { orçamento empresarial; ( ) Mensuração e avaliação dos custos; ( ) Ajustes para } \\
\text { apuração dos tributos; ( ) Determinação do valor recuperável de ativos; ( ) } \\
\text { Determinação do custo atribuído aos ativos; ( ) Determinação do ajuste a valor } \\
\text { presente; ( ) Constituição de provisões de ativos e passivos contingentes; ( ) } \\
\text { Estabelecimento e monitoramento de sistemas de controle interno; ( ) Sistemas } \\
\text { de informações contábeis, econômicos, financeiros e patrimoniais. }\end{array}$ \\
\hline
\end{tabular}

Transformações Como as pessoas da área organizacional controladoria envolvidas com a implementação das normas internacionais de contabilidade estão se adaptando a esse processo? ( ) Com leitura e discussão; ( ) Com dedicação e comprometimento; ( ) Com novas responsabilidades.

Comunicação As regras existentes na área organizacional controladoria permitiram uma comunicação fluente durante o processo de implementação das normas internacionais de contabilidade? ( ) Houve reuniões e troca de ideias entre o pessoal da controladoria; ( ) Houve reuniões e troca de ideias com áreas de apoio da controladoria; ( ) Houve reuniões e troca de ideias com a empresa de consultoria e auditoria independente.

Dominação Recursos $\quad$ A área organizacional controladoria foi a principal responsável pela autoritários coordenação do processo de implementação das normas internacionais de contabilidade? ( ) A controladoria, por meio dos seus agentes, foi a principal responsável, pela implementação das normas internacionais, por ser a área com maior domínio do processo; ( ) As áreas de apoio à controladoria foram as responsáveis pela implementação das normas internacionais, por possuírem informações necessárias para isso; ( ) A área contábil, por meio dos seus agentes, foi a principal responsável pela implementação das normas internacionais de contabilidade.

Recursos Houve mais investimento tecnológico e humano na área organizacional alocativos controladoria com a adoção das normas internacionais de contabilidade? ( ) Admissão de novas pessoas na área organizacional controladoria; ( ) Investimentos em cursos de aperfeiçoamento; ( ) Investimentos em sistemas de informação.

Facilidades Como as pessoas da área organizacional controladoria se sentiram preparadas para atingir os objetivos e alcançar os resultados almejados com o processo de adoção das normas internacionais de contabilidade? ( ) Preparadas, pois já possuíam experiências vivenciadas em outras empresas; ( ) Preparadas, pois adquiriram experiências na própria empresa, em função dos recursos investidos; ( ) Preparadas, pois, apesar de não terem experiências práticas, possuíam sólido conhecimento teórico.

Poder Como aconteceu a delegação das novas responsabilidades decorrentes da adoção das normas internacionais de contabilidade pelo controller aos subordinados? ( ) Com liderança e poder de influência; ( ) Com clareza sobre os novos procedimentos; ( ) Com exigências de novas competências na controladoria. 


\section{Tabela 1 (continuação)}

\begin{tabular}{lll}
\hline Variáveis & Subvariáveis & Perguntas \\
\hline Legitimação & Obrigações & Houve implementação de todos os Pronunciamentos Técnicos CPC, \\
& & Orientações Técnicas OCPC e Interpretações Técnicas ICPC que a empresa \\
& está obrigada a adotar? ( ) Os 14 pronunciamentos, uma norma sobre estrutura \\
& conceitual básica e uma orientação técnica, emitidos em 2008, foram \\
& implementados na empresa no respectivo ano; ( ) Os 26 pronunciamentos, \\
& duas orientações técnicas e 12 interpretações técnicas, emitidos em 2009, \\
& foram implementados na empresa no respectivo ano e em 2010; ( ) O \\
& pronunciamento, da orientação técnica e das três interpretações técnicas, \\
& emitidos em 2010, foram implementados no respectivo ano.
\end{tabular}

Sanção Houve alguma sanção durante o processo de implementação das normas internacionais de contabilidade? ( ) A controladoria passou a realizar remanejamento de funcionários; ( ) A controladoria fez advertências para funcionários que não se adaptaram ao processo; ( ) A controladoria precisou desligar funcionários que não se adaptaram ao processo.

Comportamentos $\mathrm{O}$ processo de adoção das normas internacionais de contabilidade vem legitimados provocando mudanças na conduta da controladoria, na pessoa do controller? ( ) A controladoria passou a se preocupar mais com o nível de evidenciação, devido ao aumento das exigências a partir da adoção das normas; ( ) A controladoria passou a se preocupar mais com a aceitação dos novos procedimentos, decorrentes da adoção das normas; ( ) A controladoria passou a ter maior nível de cobrança e ter uma postura mais firme em função de novos procedimentos.

Produção de

Durante o processo de implantação das normas internacionais de moralidade contabilidade, foram observados na controladoria a legitimação de normas e valores produzindo moralidade? ( ) A necessidade de convívio com outras áreas, para o levantamento de informações, como engenharia, relações com investidores, diretoria, conselho de administração, conselho fiscal, gerou novas regras de convivência; ( ) A adoção das normas internacionais de contabilidade gerou novas atividades na área organizacional controladoria, que precisaram ser executadas por outras áreas da organização, mediante pressões morais e sociais; ( ) A adoção das normas internacionais de contabilidade gerou novas atividades, que colocaram em evidência a missão da área organizacional controladoria.

\begin{tabular}{lll}
\hline Significação & $\begin{array}{l}\text { Produção e } \\
\text { reprodução. }\end{array}$ & Todas as acima destacadas. \\
Dominação & $\begin{array}{l}\text { Dualidade da } \\
\text { estrutura }\end{array}$ & \\
Legitimação &
\end{tabular}

Observa-se, na Tabela 1, que para cada variável constituíram-se subvariáveis e respectivas perguntas. As variáveis e subvariáveis foram baseadas nos estudos de Macintosh e Scapens (1990, 1991), Barrachina (2001), Giddens (2003), Junquilho (2003) e Busco (2009). O questionário constituiuse de quatro blocos: um geral, com dados de identificação do participante, e os demais cada um com quatro perguntas, sendo um bloco para avaliar a significação, outro para a dominação, e um terceiro para a legitimação.

Todas as perguntas compreenderam assertivas com escala Likert de zero a quatro, sendo zero (0) nenhum impacto, nenhuma presença ou nenhuma normativa implementada, e quatro (4) forte impacto, forte presença ou todas as normativas implementadas. Utilizou-se a escala de cinco pontos, de zero a quatro, para analisar o grau da presença, do impacto ou da implementação das situações apresentadas no questionário, nas empresas objeto de estudo. Por exemplo, o impacto da adoção das normas internacionais de contabilidade, em determinada função da controladoria, pode variar de zero, quando não existir impacto, a quatro, quando for de forte impacto. 
Apesar de não recomendada por alguns autores (Fávero, Belfiore, Chan, \& Silva, 2009) para além de uma composição de frequências, de acordo com Martins e Theóphilo (2009), a escala Likert é bastante utilizada em pesquisas sociais. Na survey, o sujeito externa sua reação ante assertivas, escolhendo os pontos de uma escala. O somatório dos pontos indicará sua atitude positiva ou negativa em relação ao objeto. Há casos em que os pesquisadores utilizam valores de 0 a 4 ou de -2 a +2 , considerando uma pontuação alta ou baixa, segundo o número de itens e os valores atribuídos a cada ponto da escala.

Ressalta-se ainda que as perguntas foram elaboradas com base nos estudos de Macintosh e Scapens (1990, 1991), Barrachina (2001), Giddens (2003), Junquilho (2003) e Busco (2009). Inicialmente, as perguntas foram elaboradas e aplicadas em um estudo piloto, realizado na forma de estudo de caso em uma indústria têxtil, já com vistas nessa pesquisa. Para o estudo piloto elaboraramse 12 questões abertas, quatro para cada pilar. Neste estudo, elas foram transformadas para questões de múltipla escolha, mantendo-se o foco da pergunta.

Antes da aplicação do questionário realizou-se um pré-teste com dois controllers de empresas e um aluno de doutorado com experiência nas atribuições, funções e atividades da área organizacional da controladoria. Alguns ajustes de redação foram efetuados em questões com base nas sugestões apresentadas, mas como se referiam basicamente a correções gramaticais e à concordância verbal, o questionário não foi encaminhado para outros juízes.

\section{Hipóteses da pesquisa e justificativa}

Para a formulação das hipóteses, utilizaram-se estudos fundamentados na Teoria da Estruturação de pesquisas em contabilidade (Busco, 2009; Macintosh \& Scapens, 1990) e de administração (Cánepa, Brodbeck, \& Fetzner, 2008; Junquilho, 2003). A partir do problema da pesquisa e dos fundamentos teóricos, formularam-se as seis hipóteses que seguem.

Macintosh e Scapens (1990) expõem que os conceitos possuem significação, na medida em que os atores sociais compartilham o entendimento de seus significados. Com o processo de convergência, surgiram atividades que a controladoria precisou desenvolver, alterando suas funções e, consequentemente, a rotina das pessoas envolvidas. As transformações de processos e sistemas para atender às novas exigências e o entendimento das novas atividades exige maior comunicação entre os agentes, ou seja, maior interação nessa área organizacional.

De acordo com Busco (2009), as práticas contábeis desempenham papel importante na relação recursiva entre interação (ação dos agentes) e estrutura (regras e recursos) nas modalidades de estruturação. Assim, espera-se uma inter-relação entre os elementos que formam o pilar de significação na controladoria, com a adoção das normas internacionais de contabilidade. Diante disso, levantou-se a seguinte hipótese:

$\mathbf{H}_{1}$ : Existe inter-relacionamento entre os elementos do pilar de significação.

Nessa hipótese, pretende-se concluir que os elementos do pilar de significação se inter-relacionam na controladoria com a adoção das normas internacionais de contabilidade, existindo uma dualidade entre a estrutura de significação e a interação de comunicação.

A dominação "está fortemente relacionada com o conceito de poder" (Busco, 2009, p. 258). Em sentido amplo, poder é "a capacidade de fazer as coisas e fazer a diferença no mundo" (Macintosh \& Scapens, 1990, p. 461). Em sentido estrito, poder representa dominação (Busco, 2009). Desse modo, "os sistemas de contabilidade gerencial são concebidos como recursos socialmente construídos, que podem ser desenhados sob o exercício do poder em ambos os sentidos" (Busco, 2009, p. 258). Com base na estrutura de dominação, alguns membros da organização mantêm outros membros responsáveis por atividades específicas (Macintosh \& Scapens, 1990).

Pressume-se que a controladoria seja a principal responsável nas organizações pelo processo de convergência, apresentando capacidade e facilidade para gerenciar os recursos e alcançar os objetivos 
almejados com esse processo, gerando uma inter-relação entre a estrutura de dominação (recursos) e a interação (poder). Assim, espera-se uma inter-relação entre os elementos que formam o pilar de dominação na área organizacional da controladoria, com o processo de adoção das normas internacionais de contabilidade. Nesse sentido, elaborou-se a hipótese a seguir:

$\mathbf{H}_{2}$ : Existe inter-relacionamento entre os elementos do pilar de dominação.

Nessa hipótese, pretende-se concluir que os elementos do pilar de dominação se inter-relacionam na controladoria com a adoção das normas internacionais de contabilidade, existindo uma dualidade entre a estrutura de dominação e a interação na forma de poder.

Macintosh e Scapens (1990) explicam que os sistemas contábeis são essenciais na institucionalização dos direitos e obrigações dos atores sociais, pois demonstram a sua ligação com a estrutura de legitimação. Segundo Busco (2009, p. 258), os sistemas contábeis "estão profundamente implicados na reprodução de valores, e são um meio pelo qual a estrutura de legitimação pode ser utilizada na interação social dentro das organizações".

As novas obrigações dos agentes em decorrência do processo de convergência, além de gerar mudanças nas funções, atividades e recursos da controladoria, também provocaram mudanças na conduta dos agentes. Com isso, legitimaram novos comportamentos e valores, produzindo moralidade e sanção, gerando uma inter-relação entre a estrutura de legitimação (regras normativas) e a interação (sanção). Assim, espera-se uma inter-relação entre os elementos que formam o pilar de legitimação na controladoria, com a adoção das normas internacionais de contabilidade. Com base no exposto, elaborou-se a seguinte hipótese:

$\mathbf{H}_{3}$ : Existe inter-relacionamento entre os elementos do pilar de legitimação.

Nessa hipótese, pretende-se concluir que os elementos do pilar de legitimação se inter-relacionam na controladoria com a adoção das normas internacionais de contabilidade, existindo uma dualidade entre a estrutura de legitimação e a interação de sanção.

A estrutura de dominação, que compreende os recursos mobilizados nas relações de poder, está intimamente ligada às estruturas de significação e legitimação (Macintosh \& Scapens, 1990). Logo, espera-se uma forte e significativa relação do pilar de significação com o pilar de dominação na área organizacional da controladoria, com o processo de adoção das normas internacionais de contabilidade. Desse modo, levantou-se a seguinte hipótese:

H4: O pilar de significação está forte e significativamente correlacionado com o pilar de dominação.

Nessa hipótese, pretende-se concluir que existe uma ligação entre o pilar de significação e o pilar de dominação na controladoria, com o processo de adoção das normas internacionais de contabilidade.

Wanderley e Cullen (2012, p. 171) destacam em seu estudo que as mudanças na contabilidade gerencial são "sustentadas por mudanças concomitantes nos fundamentos legitimadores, estruturas de significação e perspectivas de dominação e não podem ser compreendidas adequadamente sem considerar essas três dimensões inter-relacionadas".

Conforme observado por Macintosh e Scapens (1990) e Wanderley e Cullen (2012), na perspectiva da contabilidade gerencial, espera-se uma forte e significativa correlação do pilar de dominação com o pilar de legitimação na área organizacional controladoria, com o processo de adoção das normas internacionais de contabilidade. Sendo assim, elaborou-se a hipótese a seguir:

H5: O pilar de dominação está forte e significativamente correlacionado com o pilar de legitimação.

Nessa hipótese, pretende-se concluir que existe uma ligação entre o pilar de dominação e o pilar de legitimação na controladoria, com o processo de adoção das normas internacionais de contabilidade. 
Busco (2009) menciona que, de acordo com a visão de Giddens, por confiar nas estruturas e na relação das modalidades de estruturação, a institucionalização de uma ordem socialmente construída pode ser atingida, ou seja, um quadro de significados pode ser comunicado, um sistema de autoridade e poder pode ser estabelecido e, finalmente, um código moral de conduta pode ser reconhecido.

Segundo Cánepa et al. (2008), as modalidades que ligam a estrutura com a interação se iniciam com um estágio cognitivo (significação), passam por um estágio regulativo (dominação) e finalizam-se com um estágio normativo (legitimação). Com base em Busco (2009) e Cánepa et al. (2008), elaborouse a hipótese a seguir:

H$_{6}$ : Os pilares de significação e dominação estão forte e significativamente correlacionados com o pilar de legitimação.

Nessa hipótese, pretende-se concluir que existe uma ligação entre os pilares de significação e dominação com o pilar de legitimação na controladoria, com o processo de adoção das normas internacionais de contabilidade.

\section{Análise dos dados}

A Figura 2 evidencia as etapas de análise percorridas neste estudo. Nela são apresentados o sistema social e suas propriedades estruturais pelos quais o controller e os demais envolvidos na controladoria orientam-se em suas ações diárias.

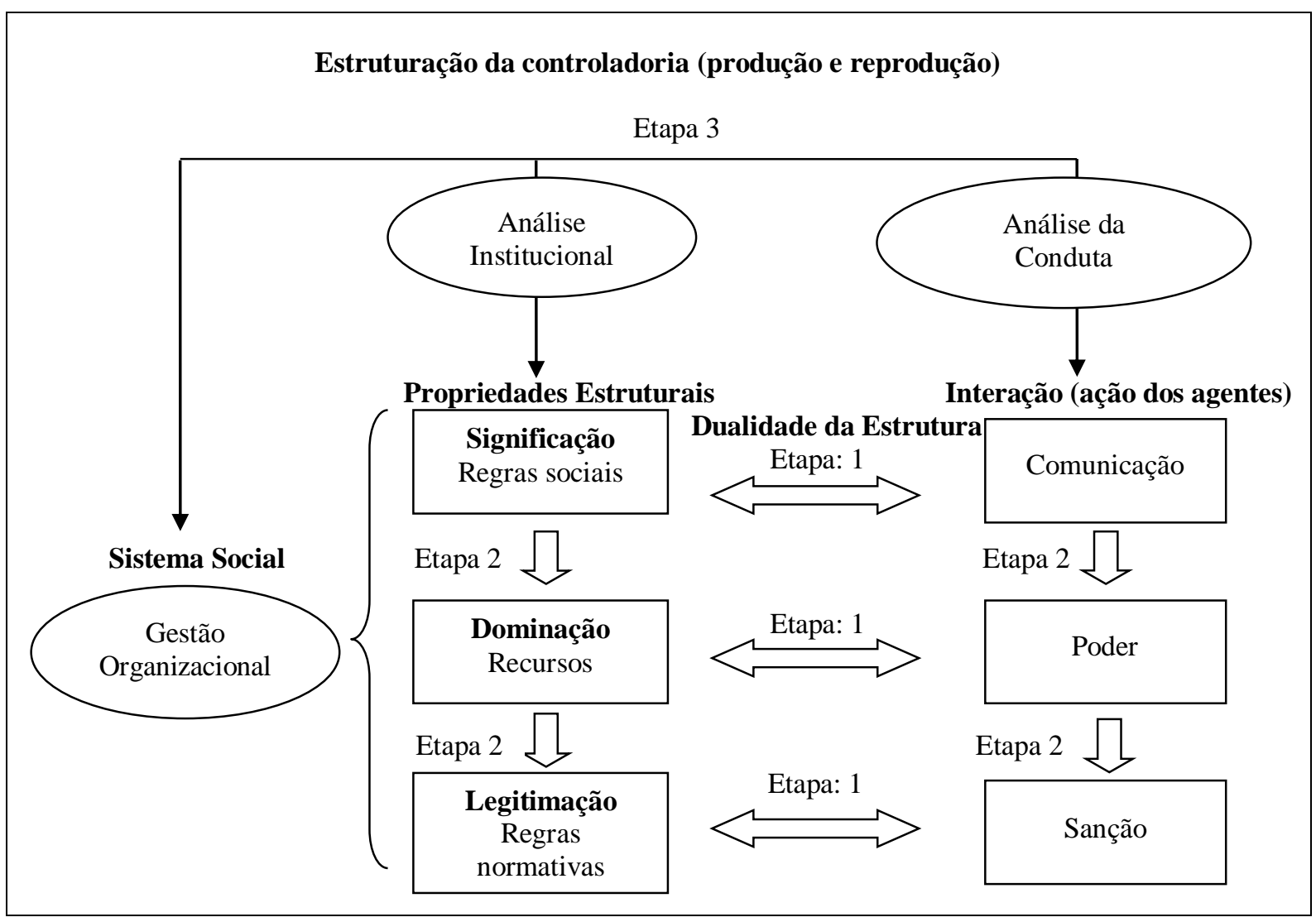

Figura 2. Esquema de Análise

Fonte: Elaboração com base em Junquilho, G. S. (2000). Ação gerencial na administração pública: a re/produção de "raizes" brasileiras (p. 97) (Tese de doutorado). Universidade Federal de Minas Gerais, BH, Brasil.

A análise dos dados foi realizada em três etapas. Na Etapa 1, apresenta-se a análise simultânea da estrutura (análise institucional) e da interação (análise da conduta estratégica), ou seja, o interrelacionamento dos elementos na controladoria. Na Etapa 2, apresenta-se a correlação entre os pilares, 
confirmando ou não a estruturação da controladoria. Na Etapa 3, faz-se uma síntese das análises efetuadas, evidenciando a estruturação da controladoria.

Para a análise da Etapa 1, foi aplicada a análise fatorial, que permite identificar o interrelacionamento das subvariáveis em cada pilar. "A análise fatorial, ou análise do fator comum, é uma técnica multivariada de interdependência que busca sintetizar as relações observadas entre um conjunto de variáveis inter-relacionadas, buscando identificar fatores comuns" (Fávero et al., 2009, p. 235).

Na Etapa 3, para se confirmar a estruturação da controladoria, ou seja, a produção e reprodução de sua ordem social, foi utilizada a correlação canônica. "O objetivo da correlação canônica é quantificar a força da relação existente entre dois vetores de variáveis, representados pelas dependentes e pelas independentes" (Fávero et al., 2009, p. 506). Com a utilização da correlação canônica, é possível identificar a relação entre os pilares.

\section{Descrição e Análise dos Dados}

\section{Inter-relacionamento dos elementos na controladoria}

Nesta seção, busca-se averiguar, dentro de cada pilar da Teoria da Estruturação, o interrelacionamento dos elementos, de acordo com o modelo da dualidade da estrutura em interação, que relaciona estrutura e interação (ação social), levando em consideração que essa relação é recíproca e acontece de forma simultânea. Para tanto, foi aplicada a análise fatorial, por meio da Análise das Componentes Principais (ACP) para as subvariáveis de cada pilar.

Para a aplicação da análise fatorial, primeiramente calcularam-se as médias, por respondente, das respostas obtidas para cada elemento e/ou subvariável em cada pilar (variável), já que, em cada pergunta, havia várias assertivas. Identificadas as médias por respondente para cada subvariável, foi aplicada a análise fatorial. Para avaliar a adequação da análise fatorial, aplicaram-se os testes Kaiser-Meyer-Olkin (KMO) e Esfericidade de Bartlett para cada pilar (variável), conforme demonstrado na Tabela 2.

Tabela 2

Resultados da Estatística KMO e do Teste de Esferecidade de Bartlett dos Pilares

\begin{tabular}{llccc} 
& & Significação & Dominação & Legitimação \\
\hline Kaiser-Meyer-Olkin (KMO) Measure of Sampling Adequacy &, 499 &, 619 &, 581 \\
\hline \multirow{2}{*}{ Bartlett's Test of Sphericity } & Approx. Chi-Square & 90,400 & 16,854 & 15,985 \\
& Df & 6 & 6 & 6 \\
& Sig. &, 000 &, 010 & 0,014 \\
\hline
\end{tabular}

Observa-se na Tabela 2 que o KMO do pilar de significação é de $0,499, \cong 0,50$, considerado estatisticamente desfavorável. No entanto, ainda é aceitável a aplicação da análise fatorial, pois, segundo Fávero, Belfiore, Chan e Silva (2009, p. 254), os valores da estatística KMO "próximos de zero indicam que a análise fatorial pode não ser adequada, já que explicitam a existência de uma fraca correlação entre as variáveis. Ao contrário, quanto mais próximos de 1, maior será a qualidade da AF". Nos pilares de dominação e legitimação, o KMO foi superior a 0,50. O nível de significância do teste de esferecidade de Bartlett, $p$-value $=0,000$, evidencia que há correlações entre as subvariáveis, o que permite utilizar a análise fatorial.

Aplicou-se ainda a matriz anti-imagem, que auxilia na análise da adequação do uso dessa técnica estatística. Segundo Maroco (2003, p. 286), "as matrizes de anti-imagem para a variância-covariância e 
para as correlações apresentam os valores negativos das covariâncias e correlações parciais entre as variáveis. Estes valores estimam as correlações entre as variáveis que não são devidas aos fatores comuns". Os resultados da matriz anti-imagem em cada pilar apontaram que todas as subvariáveis se ajustam à estrutura definida.

Na Tabela 3 apresenta-se a matriz da componente pilar de significação. Para Fávero et al. (2009, p. 256), "a matriz das componentes apresenta as cargas que correlacionam as variáveis com os fatores antes da rotação, ou seja, permite verificar qual fator melhor explica cada uma das variáveis originais".

Tabela 3

Matriz da Componente Pilar de Significação

\begin{tabular}{lc}
\hline Subvariáveis & Componente \\
\cline { 2 - 2 } & $\mathbf{1}$ \\
\hline Funções (FUN) &, 784 \\
Atividades (ATI) &, 868 \\
Transformações (TRA) &, 796 \\
Comunicações (COM) &, 814 \\
\hline
\end{tabular}

Observa-se, na Tabela 3, que nas subvariáveis funções (FUN), atividades (ATI), transformações (TRA) e comunicações (COM), houve predomínio da componente (fator) um, e todas as subvariáveis possuem cargas elevadas, pois são superiores a 75\%. Percebe-se que atividades (ATI) foi o elemento que mais se destacou, apresentando carga fatorial de 0,868 , seguido do elemento comunicações (COM), com 0,814 , após transformações (TRA) com 0,796, e, por fim, funções (FUN) com 0,784. Portanto, todos os elementos que formam a estrutura e a interação do pilar de significação, na Teoria da Estruturação de Giddens (2003), estão intensamente definidos no fator um.

Infere-se do exposto que os elementos do pilar significação apresentaram inter-relacionamento na área organizacional da controladoria com o processo de adoção das normas internacionais de contabilidade, constituindo uma única carga fatorial. As funções, atividades, transformações e comunicações foram impactadas na controladoria das empresas, existindo a dualidade da estrutura, entre a estrutura de significação e a ação dos agentes da controladoria na forma de comunicação, conforme preconizado por Giddens (2003).

$\mathrm{Na}$ Tabela 4, demonstra-se a matriz das componentes do pilar de dominação, formada por duas componentes.

Tabela 4

Matriz das Componentes do Pilar de Dominação

\begin{tabular}{lcc}
\hline Subvariáveis & \multicolumn{2}{c}{ Componentes } \\
\cline { 2 - 3 } & $\mathbf{1}$ & $\mathbf{2}$ \\
\hline Recursos Autoritários (RAU) &, 655 &,- 581 \\
Recursos Alocativos (RAL) &, 459 &, 797 \\
Facilidades (FAC) &, 806 &,- 137 \\
Poder (POD) &, 749 &, 167 \\
\hline
\end{tabular}


De acordo com a Tabela 4, na primeira componente (fator), as subvariáveis recursos autoritários (RAU), facilidades (FAC) e poder (POD) apresentaram cargas mais elevadas, 0,655, 0,806 e 0,749, respectivamente. Já na segunda componente, a subvariável recursos alocativos (RAL), com 0,797, possui carga mais elevada. Observa-se que as facilidades (que se referem às modalidades) e o poder (a interação) da Teoria da Estruturação de Giddens (2003) se concentram no fator um. Porém, os recursos autoritários (que dizem respeito à estrutura), com maior carga na primeira componente, e recursos alocativos (que se referem à estrutura), com maior carga na segunda componente, mostraram-se menos especificados.

Infere-se, assim, que as facilidades e o poder apresentaram inter-relacionamento na área da controladoria das empresas pesquisadas, durante o processo de adoção das IFRS. Isso também ocorreu com os recursos autoritários e alocativos, mas de modo menos contundente, já que esses dois elementos se apresentaram especificados de forma menos intensa. Tal resultado evidencia dualidade da estrutura, entre a estrutura de dominação e a ação dos agentes da controladoria na forma de poder, conforme proposto por Giddens (2003).

A Tabela 5 evidencia a matriz das componentes do pilar de legitimação, formada por duas delas.

Tabela 5

\section{Matriz das Componentes do Pilar de Legitimação}

\begin{tabular}{lcc}
\hline Subvariáveis & \multicolumn{2}{c}{ Componentes } \\
\cline { 2 - 3 } & $\mathbf{1}$ & $\mathbf{2}$ \\
\cline { 2 - 3 } Obrigações (OBR) &,- 375 &, 823 \\
Sanções (SAN) &, 671 &,- 275 \\
Comportamentos Legitimados (CLE) &, 831 &, 156 \\
Produção de Moralidades (PMO) &, 707 &, 514 \\
\hline
\end{tabular}

Observa-se, na Tabela 5, que, para as subvariáveis sanções (SAN), comportamentos legitimados (CLE) e produção de moralidades (PMO), há predomínio da componente (fator) um; já para o elemento obrigações (OBR), há predomínio da componente dois. Todas as subvariáveis apresentaram cargas elevadas, superiores a $65 \%$. No entanto, nem todos os elementos que formam a estrutura e a interação do pilar de legitimação, na Teoria da Estruturação de Giddens (2003), estão intensamente definidos em um fator, como é o caso das obrigações (OBR).

Depreende-se do exposto que as sanções, os comportamentos legitimados e a produção de moralidades apresentaram inter-relacionamento na área organizacional da controladoria das empresas pesquisadas durante o processo de adoção das IFRS. O elemento obrigações também pode apresentar inter-relacionamento, mas isso é menos contundente. Disso resulta a dualidade da estrutura, entre a estrutura de legitimação e a ação dos agentes da controladoria na forma de sanção, conforme proposto por Giddens (2003).

Os resultados desta pesquisa, embora realizada em campo e foco distintos, sinalizam para semelhanças com os do estudo de Macintosh e Scapens (1991), de que os sistemas de contabilidade podem legitimar as ações e as interações dos gestores no âmbito organizacional, uma vez que apresentam valores e indicam caminhos sobre o que deveria acontecer, além de institucionalizar as obrigações e os direitos dos gestores.

\section{Correlação entre os pilares na controladoria}

$\mathrm{Na}$ análise individual dos três pilares, já se constatou que, no processo de convergência contábil, a estrutura impactou na interação e a interação impactou na estrutura da controladoria. Observa-se, 
assim, a dualidade da estrutura, apesar de alguns elementos terem sido especificados de forma menos intensa na análise fatorial. Com a correlação canônica, verifica-se a correlação de um pilar com o outro, para confirmar a estruturação da controladoria, pois, de acordo com a Teoria da Estruturação de Giddens (2003), os pilares são interligados. A Tabela 6 evidencia as equações canônicas, seus coeficientes e o $p$ value de cada situação.

Tabela 6

\section{Correlações Canônicas Entre os Pilares}

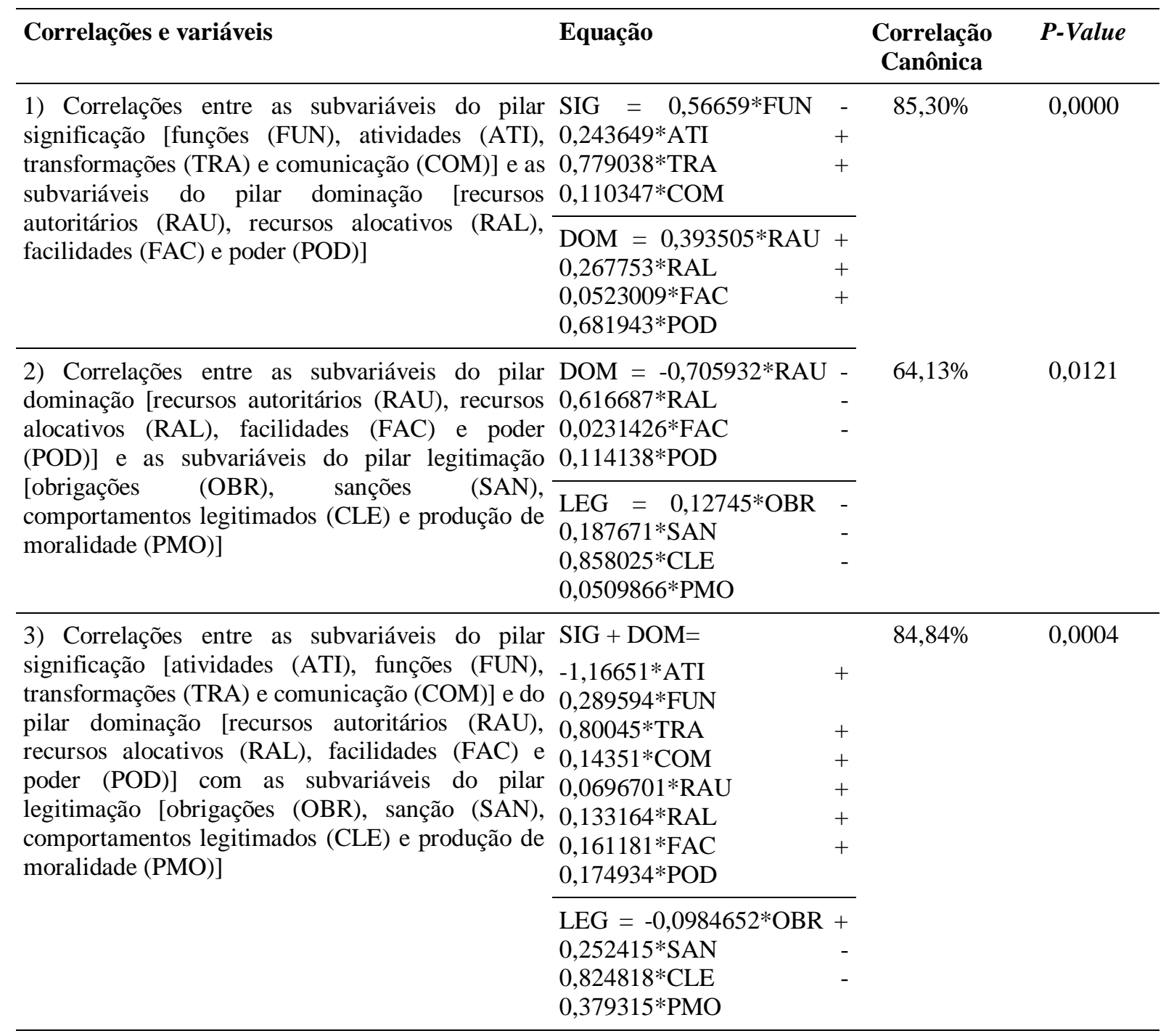

Constata-se, na Tabela 6, que as correlações um e três são consideradas fortes, pois apresentam coeficientes superiores a 70\%, embora a correlação dois seja menor, mas ainda é considerada boa, pois apresentou um percentual superior a $60 \%$. Todas as correlações possuem significância, já que apresentam um $p$-value inferior a 0,05 . Assim, consideram-se todas as correlações para análise, uma vez que são fortes, boas e apresentam significância.

Na situação 1, observa-se uma correlação de $85,30 \%$ e significância de 0,0000 , entre as subvariáveis do pilar significação e dominação. As novas regras sociais, formadas pelas funções e atividades da controladoria, e a comunicação gerada com a adoção das IFRS, estão fortemente relacionadas com a dominação da controladoria, ou seja, os recursos mobilizados nas relações de poder. A controladoria, por meio de recursos, foi a responsável pela coordenação desse processo, necessitando de investimentos tecnológicos e humanos, delegando as novas responsabilidades com poder de 
influência aos agentes da controladoria que se sentiram preparados. Tal resultado coaduna com o que mencionam Macintosh e Scapens (1990), que as estruturas de significação e dominação estão intimamente ligadas.

Na situação 2, percebe-se uma correlação de 64,13\% e significância de 0,0121 entre as subvariáveis do pilar dominação e legitimação. Macintosh e Scapens (1990) aduzem que as estruturas de dominação e legitimação estão intimamente ligadas. A dominação na controladoria, ou seja, os recursos formados pela coordenação das atividades de adoção das normas internacionais de contabilidade nesta área, os investimentos humanos e tecnológicos realizados, geraram facilidades. Os agentes se sentiram preparados para as novas responsabilidades da controladoria, com clareza nos procedimentos, liderança e poder de influência. Isso gerou a determinação de uma nova ordem social, com a obrigação da adoção dos CPCs, produzindo moralidades e legitimando comportamentos.

Na situação 3 também há forte correlação, com $84,84 \%$, e significância de 0,0004 , entre as subvariáveis dos pilares significação, dominação e legitimação. Busco (2009) preconiza, de acordo com a visão de Giddens, que as estruturas estão relacionadas, permitindo que um quadro de significados seja comunicado, um sistema de autoridade e poder estabelecido e, finalmente, um código moral de conduta reconhecido.

Cánepa et al. (2008) afirmam que a estruturação começa pelo estágio cognitivo, em seguida passa para o estágio regulativo e, por fim, para o estágio normativo. É o que se observa na controladoria com o processo de adoção das normas internacionais de contabilidade, em função da forte correlação dos três pilares. O estágio cognitivo, formado pela estrutura de significação, com as funções e as atividades da controladoria impactadas pela adoção das normas internacionais, gera a comunicação entre os agentes. O estágio regulativo na estrutura de dominação, constituído pela coordenação das atividades e poder, destaca o papel da controladoria nesse processo. O estágio normativo no pilar legitimação, produziu moralidade e comportamentos legitimados, permitindo a estruturação da controladoria.

Nas correlações canônicas entre os pilares, observaram-se as dimensões de significação, dominação e legitimação da controladoria com o processo de convergência contábil. Tal fato ocorre porque a contabilidade representa tais dimensões, conforme preconizado por Macintosh (1985), e se reflete na controladoria na medida em que ela é responsável pelas informações de suporte ao processo de gestão.

\section{Análise da estruturação da controladoria}

Nesta seção demonstra-se a estruturação (produção e reprodução da ordem social) da área organizacional controladoria, com o processo de adoção das normas internacionais de contabilidade. A Figura 3 demonstra a estruturação da ordem social da controladoria. 


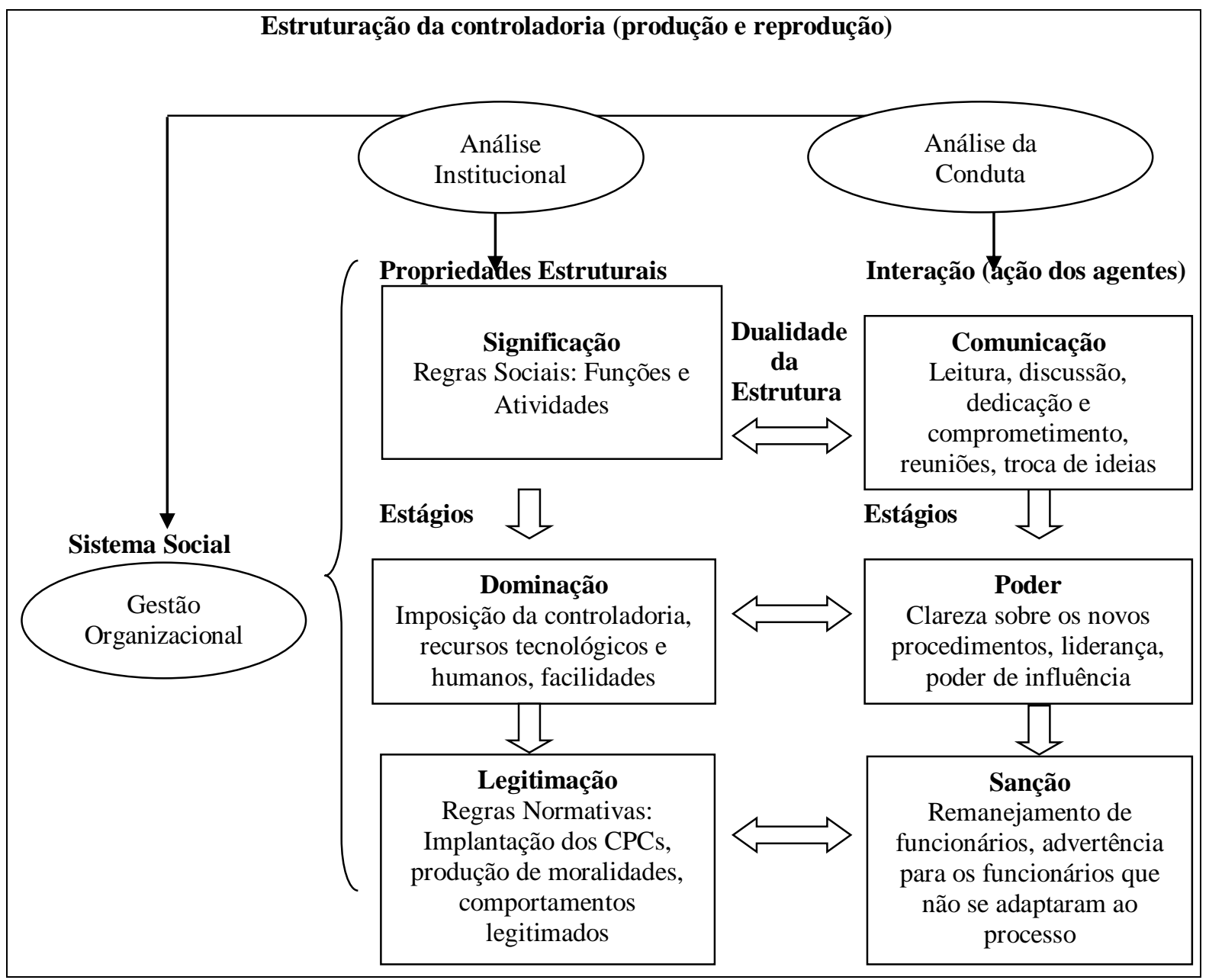

Figura 3. Estruturação da Controladoria

Na Figura 3, verifica-se que a adoção das normas internacionais de contabilidade contribuiu para a estruturação (produção e reprodução) da ordem social da área organizacional controladoria, demonstrando a presença da dualidade da estrutura, uma vez que a estrutura impactou na interação e a interação impactou na estrutura.

A estrutura da controladoria foi formada pelas regras sociais e normativas, e pelos recursos. As regras sociais foram constituídas pelas novas atividades e funções, e as normativas pela obrigatoriedade de implementação dos CPCs, produzindo moralidade e legitimando comportamentos. Os recursos autoritários constituíram-se pelas imposições por parte da controladoria no processo de adoção das normas internacionais de contabilidade e os recursos alocativos foram formados pelos recursos tecnológicos e humanos utilizados.

Essa estrutura foi influenciada pela interação dos agentes, com leitura, discussão, dedicação e comprometimento, permitindo uma comunicação fluente a partir de reuniões e troca de ideias. Os agentes também se sentiram preparados para alcançar os resultados relativos aos novos procedimentos determinados pela controladoria, com liderança e poder de influência. $\mathrm{O}$ processo provocou mudanças nas condutas na pessoa do controller, legitimando novos comportamentos, maior preocupação com os novos procedimentos, maior nível de cobrança e postura mais firme. Observou-se também a legitimação de normas e valores, colocando em evidência a missão dessa área organizacional, ou seja, produzindo moralidade, apesar de não existir tão fortemente a presença da sanção que se refere ao remanejamento de funcionários, e a advertência aos que não se adaptaram.

Esses resultados estão em consonância com os da pesquisa de Junquilho (2003), na constatação de que os gestores, por meio de suas ações, fomentaram a reprodução de propriedades estruturais. Tais 
ações também foram influenciadas pelas condições existentes na estrutura. Observa-se ainda, na Figura 3 , a relação entre os pilares, confirmando a existência dos estágios cognitivo, regulativo e normativo. Isto evidencia que os pilares de significação, dominação e legitimação estão interligados, conforme preconizado por Giddens (2003).

Conrad (2005), ao estudar a interação da agência e as estruturas de significação, dominação e legitimação, também observou dependência mútua entre agência e estrutura em processos de mudanças. Macintosh e Scapens (1990) observaram em um estudo de caso a interação das práticas contábeis nas questões de ordem social da organização. Macintosh e Scapens (1991) também identificaram em sua pesquisa que os agentes foram capazes de derrubar as estruturas existentes, ao enfrentar uma crise de enormes proporções, e estabelecer uma nova ordem social, com uma nova contabilidade e com novos sistemas de controle. Dirsmith, Heian e Covaleski (1997), ao estudar a Teoria da Estruturação dentro de seis grandes empresas de contabilidade, também observaram a interação entre a estrutura e a agência na manutenção e na transformação da ordem social dessas empresas.

\section{Síntese das hipóteses analisadas}

Na Tabela 7 apresenta-se uma síntese das hipóteses analisadas, em que se evidenciam a hipótese formulada, os resultados dos testes aplicados e se a hipótese foi rejeitada ou se falha em rejeitar a hipótese nula. Doane e Seward (2010) explicam que uma hipótese é testada contrastando suas implicações contra evidências empíricas. Assim, pode ocorrer a rejeição da hipótese nula quando ela é verdadeira, denominada de erro tipo 1, e pode-se falhar em rejeitar a hipótese nula quando ela é falsa, chamada de erro tipo II.

Tabela 7

\section{Síntese das Hipóteses Analisadas}

\begin{tabular}{|c|c|c|}
\hline Hipóteses & Testes & Situação \\
\hline $\begin{array}{l}\mathrm{H}_{1} \text { : Existe inter-relacionamento entre os } \\
\text { elementos do pilar de significação. }\end{array}$ & $\begin{array}{l}\text { Intensidade de todas as subvariáveis que } \\
\text { compõem esse pilar em um único fator na } \\
\text { análise fatorial. }\end{array}$ & $\begin{array}{l}\text { Falha-se em rejeitar a } \\
\text { hipótese nula. }\end{array}$ \\
\hline $\begin{array}{l}\mathrm{H}_{2} \text { : Existe inter-relacionamento entre os } \\
\text { elementos do pilar de dominação. }\end{array}$ & $\begin{array}{l}\text { Dois fatores. No primeiro, concentraram- } \\
\text { se as subvariáveis recursos autoritários, } \\
\text { facilidades e poder. No segundo, os } \\
\text { recursos alocativos. }\end{array}$ & $\begin{array}{l}\text { Falha-se em rejeitar a } \\
\text { hipótese nula. }\end{array}$ \\
\hline $\begin{array}{l}\mathrm{H}_{3} \text { : Existe inter-relacionamento entre os } \\
\text { elementos do pilar de legitimação. }\end{array}$ & $\begin{array}{l}\text { Dois fatores. No primeiro se concentraram } \\
\text { as subvariáveis sanções, comportamentos } \\
\text { legitimados e produção de moralidades. } \\
\text { No segundo, obrigações. }\end{array}$ & $\begin{array}{l}\text { Falha-se em rejeitar a } \\
\text { hipótese nula. }\end{array}$ \\
\hline $\begin{array}{l}\mathrm{H}_{4}: \text { O pilar de significação está forte e } \\
\text { significativamente correlacionado com o } \\
\text { pilar de dominação. }\end{array}$ & Significância e forte correlação. & $\begin{array}{l}\text { Falha-se em rejeitar a } \\
\text { hipótese nula. }\end{array}$ \\
\hline $\begin{array}{l}\mathrm{H}_{5}: \text { O pilar de dominação está forte e } \\
\text { significativamente correlacionado com o } \\
\text { pilar de legitimação. }\end{array}$ & Significância e boa correlação. & $\begin{array}{l}\text { Rejeita-se } \\
\text { parcialmente a } \\
\text { hipótese nula. }\end{array}$ \\
\hline $\begin{array}{l}\mathrm{H}_{6}: \text { Os pilares de significação e } \\
\text { dominação estão forte e } \\
\text { significativamente correlacionados com o } \\
\text { pilar de legitimação. }\end{array}$ & Significância e forte correlação. & $\begin{array}{l}\text { Falha-se em rejeitar a } \\
\text { hipótese nula. }\end{array}$ \\
\hline
\end{tabular}

De acordo com a Tabela 7, falha-se em rejeitar a hipótese nula de $\mathrm{H}_{1}, \mathrm{H}_{2}, \mathrm{H}_{3}, \mathrm{H}_{4}$ e $\mathrm{H}_{6}$, além de rejeitar-se parcialmente a hipótese nula da $\mathrm{H}_{5}$, visto que o processo de adoção das normas internacionais 
de contabilidade impactou a área organizacional da controladoria, provocando a produção e a reprodução da sua ordem social. Embora o teste da hipótese $\mathrm{H}_{5}$ tenha apresentado significância, com um p-value de 0,0121 , portanto, inferior a 0,05 , a correlação foi de $64,13 \%$. Ainda que a correlação tenha ficado acima de $60 \%$, ela é caracterizada apenas como boa, e isso implicou rejeitar parcialmente a hipótese $\mathrm{H}_{5}$, já que se previa uma correlação forte e significante entre os pilares de dominação e de legitimação.

\section{Conclusões}

Buscando compreender a dinâmica do campo do órgão organizacional da controladoria, fundamentado em um quadro estruturacionista, nas dimensões de legitimação, significação e dominação, o estudo objetivou verificar o impacto da adoção das normas internacionais de contabilidade, sob a lente da Teoria da Estruturação, na área da controladoria de empresas do novo mercado da BM\&FBovespa.

Os resultados da pesquisa mostraram que, no pilar de significação, todas as subvariáveis, funções, atividades, transformações e comunicação se destacaram, constituindo um único fator, demonstrando uma inter-relação entre os elementos. No pilar de dominação, destacaram-se dois componentes, um formado pelos recursos autoritários, facilidades e poder; e outro pelos recursos alocativos, ou seja, houve inter-relacionamento entre os elementos. No pilar legitimação também resultaram dois fatores em que sanção, comportamentos legitimados e produção de moralidade formaram o primeiro fator; e obrigações formou o segundo fator.

Observou-se, assim, a dualidade da estrutura na área organizacional da controladoria com a adoção das normas internacionais, com a estrutura (significação, dominação e legitimação), influenciando a ação dos agentes (comunicação, poder e sanção) e a ação influenciando a estrutura. Esses resultados estão em linha com o preconizado na Teoria da Estruturação, conforme descrito por Macintosh e Scapens (1990), e com a proposição de Giddens (2003), de que as regras e os recursos esboçados na produção e na reprodução da ação social são, ao mesmo tempo, os meios de reprodução do sistema.

Constatou-se também uma correlação forte e significativa entre os elementos dos pilares de significação e dominação, e dos pilares de significação e dominação com o pilar de legitimação. A correlação entre os pilares de dominação e legitimação foi boa e significativa. Tais correlações evidenciam a transição dos estágios, cognitivo, regulativo e normativo durante o processo de convergência, demonstrando a interligação entre os pilares. Assim, reforça-se a observação de Cánepa et al. (2008), de que a estruturação começa por um estágio cognitivo, passa para um regulativo e evolui para um normativo.

Portanto, na análise da estruturação (produção e reprodução da ordem social) da área organizacional controladoria, com o processo de adoção das normas internacionais, constatou-se a estruturação da controladoria. Em outras palavras, houve a produção e a reprodução da sua ordem social por meio da dualidade da estrutura em interação, e pelos estágios que a mesma transitou durante o processo de convergência das normas brasileiras às normas internacionais de contabilidade. Isso confirma a adequação da Teoria da Estruturação (Macintosh, 1985) para analisar as dimensões de legitimação, significação e dominação, e o papel da agência nas mudanças da controladoria com a convergência contábil.

No teste das hipóteses, falhou-se em rejeitar a hipótese nula de $\mathrm{H}_{1}$ : Existe inter-relacionamento entre os elementos do pilar de significação; $\mathrm{H}_{2}$ : Existe inter-relacionamento entre os elementos do pilar de dominação; $\mathrm{H}_{3}$ : Existe inter-relacionamento entre os elementos do pilar de legitimação; $\mathrm{H}_{4}$ : $\mathrm{O}$ pilar de significação está forte e significativamente correlacionado com o pilar de dominação; e $\mathrm{H}_{6}$ : Os pilares de significação e dominação estão forte e significativamente correlacionados com o pilar de legitimação. 
Além disso, ocorreu a rejeição parcial da hipótese nula de $\mathrm{H}_{5}$ : $\mathrm{O}$ pilar de dominação está forte e significativamente correlacionado com o pilar de legitimação.

Confirma-se, desse modo, que a adoção do processo de convergência das normas internacionais de contabilidade nas empresas pesquisadas impactou na área da controladoria, provocando a produção e a reprodução da sua ordem social. Os resultados da pesquisa coadunam com os de Macintosh e Scapens (1990, 1991), Dirsmith et al. (1997), Junquilho (2003) e Conrad (2005), de que a interação entre a estrutura e a agência influencia na transformação da ordem social. A rejeição parcial da $\mathrm{H}_{5}$ pode decorrer do fato de não ser forte a presença de sanções, como remanejamento de funcionários e advertência aos que não se adaptaram. Beuren e Almeida (2012) também observaram pouca presença de direitos e sanções, possivelmente justifica-se pela conotação normativa do processo.

Conclui-se que o processo de adoção das normas internacionais de contabilidade impactou na área da controladoria, provocando a produção e a reprodução de sua ordem social, ou seja, a sua estruturação. O pilar de significação foi o que mais sofreu impacto, seguido dos pilares de dominação e legitimação. Ressalta-se, todavia, que esses resultados limitam-se à amostra de empresas pesquisadas e não podem ser extrapolados para além das técnicas estatísticas utilizadas, logo não podem ser generalizados, sendo que estudos em outras empresas e a aplicação de outras técnicas estatísticas podem levar a diferentes conclusões.

O estudo contribui para identificar, em uma visão estruturacionista, as mudanças que o processo de adoção dessas normas contábeis provocou na área da controladoria, em suas funções e procedimentos, e na conduta de seus agentes. No entanto, recomenda-se que outras empresas sejam pesquisadas, considerando um período de investigação em que a adoção das normas internacionais de contabilidade esteja mais consolidada. Recomenda-se ainda que as subvariáveis, criadas a partir das variáveis extraídas do referencial teórico, sejam adaptadas e/ou replicadas para outros contextos, com reflexões sobre a utilização das questões e assertivas elaboradas neste estudo em outro campo de pesquisa.

\section{Referências}

Almeida, L. B., Parisi, C., \& Pereira, C. A. (1999). Controladoria. In A. Catelli (Coord.), Controladoria: uma abordagem da gestão econômica - GECON (pp. 369-381). São Paulo: Atlas.

Almeida, M. L., \& Sales, R. S. F. (2011, novembro). A estratégia como prática e a teoria da estruturação: distâncias e aproximações. Anais do Encontro de Gestão de Pessoas e Relações de Trabalho da $A N P A D$, João Pessoa, PB, Brasil, 3.

Angelkort, H., Sandt, J., \& Weißenberger, B. E. (2008). Controllership under IFRS: some critical observations from a German-speaking country [Working Paper ${ }^{\circ}{ }^{1}$ ]. Giessen Electronic Library. Retrieved from http://geb.uni-giessen.de/geb/volltexte/2008/5397/pdf/ApapIMC_2008_01.pdf

Araújo, P. P. (2003). Nuevo institucionalismo, teoría de la estructuración y cambio en los sistemas y prácticas de contabilidad de gestión: teorías y métodos de investigación. Revista Española de Financiación y Contabilidad, 32(118), 693-724.

Barley, S. R., \& Tolbert, P. S. (1997). Institutionalization and structuration: studying the links between action and institution. Organization Studies, 18(1), 93-117. doi: 10.1177/017084069701800106

Barrachina, M. P. (2001). Enfoque económico: social de los sistemas contables de gestión: problemática del cambio contable (Tesis de doctorado). Universitat de València, Espanha.

Barrachina, M. P., \& Ripoll, V. M. F. (2006). La teoría de estructuración en la investigación de la contabilidad de gestión. Problemática del cambio contable. Revista de Contabilidad y Dirección, $3(3), 151-176$. 
Berger, P., \& Luckmann, T. (1973). A construção social da realidade (4a ed.). Petrópolis: Vozes.

Beuren, I. M., \& Almeida, D. M. (2012). Impactos da implantação das normas internacionais de contabilidade na controladoria: um estudo à luz da teoria da estruturação em uma empresa têxtil. Revista de Administração, 47(4), 653-670. doi: 10.5700/rausp1065

Bolsa de Valores, Mercadorias e Futuros Bovespa. (n.d.). Empresas listadas. Recuperado de http://www.bmfbovespa.com.br/Cias-Listadas/Empresas-

Listadas/BuscaEmpresaListada.aspx?idioma=pt-br

Burns, J., \& Scapens, R. W. (2000). Conceptualizing management accounting change: an institutional framework. Management Accounting Research, 11(1), 3-25. doi: 10.1006/mare.1999.0119

Busco, C. (2009). Giddens structuration theory and its implications for management accounting research. Journal of Management and Governance, 13(3), 249-260. doi: 10.1007/s10997-0089081-6

Cánepa, P. C. V., Brodbeck, A. F., \& Fetzner, M. A. M. (2008, setembro). Abordagens teóricas na compreensão das relações sociais na implementação da Tecnologia de Informação (TI). Anais do Encontro Nacional da Associação Nacional de Pós-Graduação e Pesquisa em Administração, Rio de Janeiro, RJ, Brasil, 23.

Conrad, L. (2005). A structuration analysis of accounting systems and systems of accountability in the privatised gas industry. Critical Perspectives on Accounting, 16(1), 1-26. doi: 10.1016/S10452354(02)00212-5

Costa, A. M., \& Carvalho, J. L. S. (2006, maio). O discurso da responsabilidade social empresarial no Brasil sob a perspectiva da teoria da estruturação. Anais do Encontro da Divisão de Estudos Organizacionais da ANPAD, Porto Alegre, RS, Brasil, 4.

Dirsmith, M. W., Heian, J. B., \& Covaleski, M. A. (1997). Structure and agency in an institutionalized setting: the application and social transformation of control in the big six. Accounting Organizations and Society, 22(1), 1-27. doi: 10.1016/S0361-3682(96)00005-0

Doane, D. P., \& Seward, L. E. (2010). Estatística aplicada à administração e à economia. Porto Alegre: Artmed.

Fávero, L. P., Belfiore, P., Chan, B. L., \& Silva, F. L. (2009). Análise de dados: modelagem multivariada para tomada de decisões. Rio de Janeiro: Elsevier.

Giddens, A. (1979). Central problems in social theory. Berkeley: University of California.

Giddens, A. (1996). Novas regras do método sociológico (2a ed.). Lisboa: Gradiva.

Giddens, A. (2003). A constituição da sociedade. São Paulo: Martins Fontes.

Hopwood, A. G. (1987). The archaeology of accounting systems. Accounting Organizations and Society, 12(3), 207-234. doi: 10.1016/0361-3682(87)90038-9

Junquilho, G. S. (2000). Ação gerencial na administração pública: a re/produção de "raízes" brasileiras (Tese de doutorado). Universidade Federal de Minas Gerais, BH, Brasil.

Junquilho, G. S. (2003). Condutas gerenciais e suas raízes: uma proposta de análise à luz da Teoria da Estruturação [Edição Especial]. Revista de Administração Contemporânea, 7, 101-120. doi. 10.1590/S1415-65552003000500006

Lei n. 11.638, de 28 de dezembro de 2007. (2007). Altera e revoga dispositivos da Lei n. 6.404, de 15 de dezembro de 1976, e da Lei n. 6.385, de 7 de dezembro de 1976, e estende às sociedades de 
grande porte disposições relativas à elaboração e divulgação de demonstrações financeiras. Diário Oficial da União: edição extra. Brasília, DF.

Lima, G. S, \& Carvalho, A. M., Neto (2011, novembro). Uma leitura da evolução das teorias sobre liderança à luz da teoria da estruturação de Giddens. Anais do Encontro de Gestão de Pessoas e Relações de Trabalho da ANPAD, João Pessoa, PB, Brasil, 3.

Machado-da-Silva, C. L., Guarido, E. R., Filho, \& Rossoni, L. (2006). Campos organizacionais e estruturação: reflexões e possibilidade analíticas [Edição Especial]. Revista de Administração Contemporânea, 10, 159-196. doi: 10.1590/S1415-65552006000500009

Machado-da-Silva, C. L., \& Rossoni, L. (2007). Persistência e mudança de temas na estruturação do campo científico da estratégia em organizações no Brasil. Revista de Administração Contemporânea, 11(4), 33-58. doi: 10.1590/S1415-65552007000400003

Macintosh. N. B. (1985). The social software of accounting and information systems. Chichester: John Wiley \& Sons.

Macintosh, N. B., \& Scapens, R. W. (1990). Structuration theory in management accounting. Accounting, Organizations and Society, 15(5), 455-477. doi: 10.1016/0361-3682(90)90028-S

Macintosh, N. B., \& Scapens, R. W. (1991). Management accounting and control systems: a structuration theory analysis. Journal of Management Accounting Research, 3, 131-158.

Maroco, J. (2003). Análise estatística: com utilização do SPSS (2a ed.). Lisboa: Edições Sílabo.

Martins, G. A., \& Theóphilo, C. R. (2009). Metodologia da investigação científica para ciências sociais aplicadas. São Paulo: Atlas.

Miller, P. (1994). Accounting as social and institutional practice: an introduction. In A. G. Hopwood \& P. Miller (Coords.), Accounting as social and institutional practice (pp. 3-39). New York: Cambridge University Press.

Miller, P. (2001). Governing by numbers: why calculative practices matter. Social Research, 68(2), 379396.

Moore, D. R. J. (2011). Structuration theory: the contribution of Norman Macintosh and its application to emissions trading. Critical Perspectives on Accounting, 22(2), 212-227. doi: 10.1016/j.cpa.2010.06.011

Mosimann, C. P., \& Fisch, S. (1999). Controladoria: seu papel na administração de empresas (2a ed.). São Paulo: Atlas.

Niyama, J. K. (2009). Contabilidade internacional. São Paulo: Atlas.

Nogueira, A. C. L. (2010, maio). O conceito de rotinas em estudos organizacionais: comparação entre o paradigma funcionalista e a teoria da estruturação. Anais do Encontro da Divisão de Estudos Organizacionais da ANPAD, Florianópolis, SC, Brasil, 6.

Oliveira, V. A., \& Lemes, S. (2011). Nível de convergência dos princípios contábeis brasileiros e norteamericanos às normas do IASB: uma contribuição para a adoção das IFRS por empresas brasileiras. Revista Contabilidade \& Finanças, 22(56), 155-173. doi: 10.1590/S151970772011000200003

Peci, A. (2003). Estrutura e ação nas organizações: algumas perspectivas sociológicas. Revista de Administração de Empresas, 43(1), 24-35. doi: 10.1590/S0034-75902003000100004 
Roberts, J., \& Scapens, R. (1985). Accounting systems and systems of accountability-understanding accounting practices in their organizational context. Accounting, Organizations and Society, 10(4), 443-456. doi: 10.1016/0361-3682(85)90005-4

Rodrigues, A. L. (2008). Tensões entre econômico e social: uma proposta de análise à luz da teoria da estruturação. Revista de Administração de Empresas, 48(2), 37-50. doi: 10.1590/S003475902008000200004

Taipaleenmäki, J., \& Ikaheimo, S. (2011). On the convergence of financial accounting and management accounting: the role of information technology in accounting change [Working Papers Series]. Social Science Research Network. Retrieved from http://papers.ssrn.com/sol3/papers.cfm?abstract_id=1963638

Vatter, W. J. (1950). Accounting education for controllership. The Accounting Review, 25(3), 236-250.

Wanderley, C. A. de, \& Cullen, J. (2012). Um caso de mudança na contabilidade gerencial: a dinâmica política e social. Revista de Contabilidade \& Finanças, 23(60), 161-172. doi: 10.1590/S151970772012000300002

Weffort, E. F. J. (2005). O Brasil e a harmonização contábil internacional: influências dos sistemas jurídico e educacional, da cultura e do mercado. São Paulo: Atlas.

\title{
Dados dos Autores
}

\author{
Ilse Maria Beuren \\ Campus Reitor João David Ferreira Lima, Centro Socioeconômico, Trindade, 88040-970, Florianópolis, SC, Brasil. E-mail: \\ ilse.beuren@gmail.com \\ Dalci Mendes Almeida \\ Rua Antônio da Veiga, 140, Sala D 202, Victor Konder, 89012-900, Blumenau, SC, Brasil. E-mail: dalci.almeida@unisul.br
}

